\title{
Effect of Ambient Temperature on Dawn Chorus of House Sparrows
}

\author{
Nail M Hasan ${ }^{*}$, Motasim Badri \\ Department of Basic Sciences, College of Science \& Health Professions, Saudi Arabia
}

Copyright $\bigcirc 2016$ by authors, all rights reserved. Authors agree that this article remains permanently open access under the terms of the Creative Commons Attribution License 4.0 International License

\begin{abstract}
House sparrows (Passer domesticus) are omnipresent. Their study in different environments can shed light on effects of environment on bird behaviour. Therefore, the start of singing of house sparrows was studied all year round in a university housing compound with almost zero traffic noise in an arid dry desert climate. Sparrows start dawn chorus unusually early towards the end of January which is marked by increasing ambient temperatures and photoperiod and also coincides with the breeding season. Evidence that daily start of singing is directly and significantly influenced by major daily fluctuations in temperature during January and February is shown. Birds continue with early singing from March until July regardless of minor temperature fluctuations. Sparrows revert to late singing towards end of July. July is marked by the beginning of decreasing photoperiod but has no substantial fluctuations in temperature. The effect of climate on start of singing is discussed. This investigation is only concerned and concentrates on the shifting from normal start of singing to very early singing in spring season. It is concluded that early singing is initiated by increasing temperatures and is susceptible to daily fluctuations only early in the season and that these birds must have evolved to start their daily activities by singing early and foraging before temperature becomes very hot upon sunrise.
\end{abstract}

Keywords Dawn Chorus, Sparrows, Weather, Humidity, Climate, Desert

\section{Introduction}

Different song birds start singing (dawn chorus) at different times before sunrise depending on species. It is a geographically widespread regular phenomenon and typically begins 30-90 minutes before sunrise [1]. The song input intensity and duration noticeably increase during the breeding season. The dawn chorus in all its aspects is likely to be the result of a number of social, environmental and intrinsic factors [2,3]. Many theories give explanation to dawn chorus phenomenon $[4,5]$.

The common house sparrows (Passer domesticus) are the main singing residential birds that are widely spread in Riyadh area. They are found in house gardens and residential areas all year round. They can be observed and heard singing all year round before sunrise until sunset.

Weather conditions are major factors in influencing all aspects of bird activity including singing and foraging [6]. Dawn chorus is influenced by both abiotic and biotic environmental factors. Ambient temperature and humidity are two major abiotic factors [7] that can influence the occurrence of dawn chorus.

A recent study of the influence of weather and ambient temperature on the start of dawn chorus in several temperate North American birds [3] has shown that ambient temperature is one of the factors that can affect the start of dawn chorus.

There is a lot of research and literature regarding all aspects of dawn chorus but there are only few studies that reported a real shift to an earlier start of dawn chorus. Playback simulation of territorial intrusion caused a very small shift (4 minutes) in Black-capped Chickadees (Poecile atricapillus) [8]. Light [9] and noise [10] pollution are anthropogenic factors that were reported by many and found to influence the start of dawn chorus of urban birds. Exposure of song birds to artificial night light was also shown to cause earlier start of dawn chorus [11]. Another factor that might cause an early start of dawn chorus is anthropogenic noise. Two out of six species started dawn chorus earlier in a study of the effect of traffic noise on song birds [12].

An earlier study of the effect of weather condition and other environmental factors on 3 bird species including sparrows in a different climate zone showed that small seasonal variation in the singing time is observed but it was not to the extent shown in this study and no direct effect of temperature was observed [13].

Ambient temperature especially at night has been shown to influence the song output of dawn chorus of some birds $[14,15]$ but the influence on the start of dawn chorus was not investigated. In addition to ambient temperature, wind and 
humidity are major abiotic factors that can increase the intensity and occurrence of dawn chorus [7].

It is shown in this investigation that the main factor that can cause obvious and significant changes in the start of dawn chorus is ambient temperature. Therefore, it is concluded that desert climate / extreme weather conditions can cause changes in start of dawn chorus in the same bird species. The aim of this work is to solicit similar investigations in different weather conditions and locations for comparison to be used as records (data) in future environmental and behavioural investigations.

\section{Methods}

The start of dawn chorus for sparrows was recorded for the whole year at King Saud bin AbdulAziz University for Health Sciences Housing Compound that is located at the eastern perimeter of Riyadh city, $24^{0} 76^{\prime} \mathrm{N}_{46^{0}} 86^{\prime} \mathrm{E}$. Altitude is $576 \mathrm{~m}$ above sea level. This is a new, very quiet and very large recently inhabited housing compound with lots of shrubs, trees (mainly Palm) and open green spaces. It has almost zero traffic noise (noise level did not exceed 40 $\mathrm{dB}$ ) but it is well lit during nights. It is located within King AbdulAziz Medical City of National Guard Health Affairs and adjacent to Medical City large Housing Compounds as well. The climate of Riyadh, Saudi Arabia is marked by high temperatures during the day and somehow moderate to low temperatures at night. Most of the country follows the pattern of desert climate. It is noteworthy to say that day temperatures seldom get below $10{ }^{0} \mathrm{C}$ while night temperatures can go below $10{ }^{\circ} \mathrm{C}$ and may get close to zero degrees during January and February (figures 2).

It is conceived that the breeding season for these birds start sometime in February. Birds were actually seen nesting on the $17^{\text {th }}$ of February this year. Young sparrows were seen flying with their parents and begging for food by the middle of March 2015.

The start of dawn chorus was recorded on a calendar that shows times for dawn, sunrise and sunset. The difference between the start of singing and sunrise is calculated and plotted against different variables using Excel 2010 software.

\subsection{Criteria for Recording Start of Dawn Chorus}

The exact number of singing birds was not determined but there has to be more than one incidence of continued singing at more than one position to be considered as true start of dawn chorus thus avoiding any accidental odd singing. Normally there are more than two positions that start singing continuously within few minutes of each other.

\subsection{Measurement of Weather Parameters}

Minimum night temperatures were taken at time of singing using Samsung Android Temperature app and confirmed by car thermometer that measures outside temperature. This time at dawn is the coldest during nights. This can also be confirmed by following the hourly forecast during nights in Riyadh. Maximum day temperatures and other parameters such as humidity were taken from appropriate websites (weatherolnline.co.uk, www.accuweather.com/en/sa/riyadh).

Photoperiod (Day length) was taken from (www.riyadh.climatemps.com/sunlight.php). The second half of March 2105 witnessed the occurrence of occasional rain / showers and therefore a sharp increase in relative humidity which gave us the chance to study effect of humidity on start of singing.

\subsection{Measurement of Noise Pollution}

Noise pollution at this site was found to be $\leq 35 \mathrm{~dB}$ using an android noise pollution app. Other sites in Riyadh city where there is moderate to high traffic measured $\geq 65 \mathrm{~dB}$.

\subsection{Statistical Analysis}

Pearson correlation coefficient was calculated to determine the strength of association between start of dawn chorus and daily ambient temperature. Early morning chorus was correlated separately with day and night temperatures for the months of January, February and March 2015. The correlation coefficient was considered significant if the test p-value was $<0.05$.

\section{Results}

The relationship between photoperiod (day length) and the average start of singing for sparrows for a whole year is shown in Figure 1. The figure shows that the start of early singing which occurs in January / February coincided with the increase of day length. It also shows that the return to late singing coincided with the start of decrease in day length. The figure also shows that the biggest variations (error bars) are noticed in January and February. 


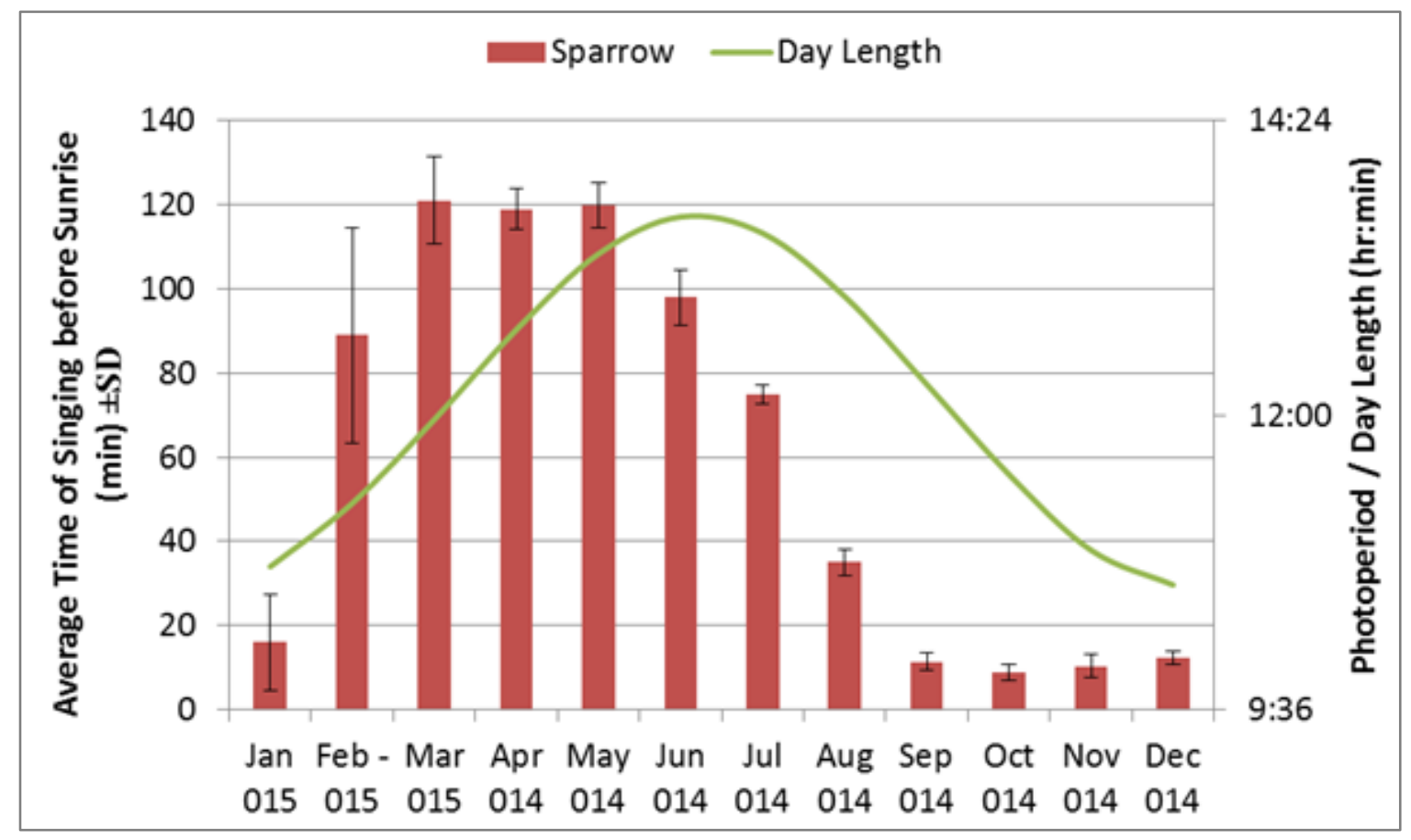

Figure 1. Relationship between photoperiod (day length) and the average start of singing for sparrows for a whole year

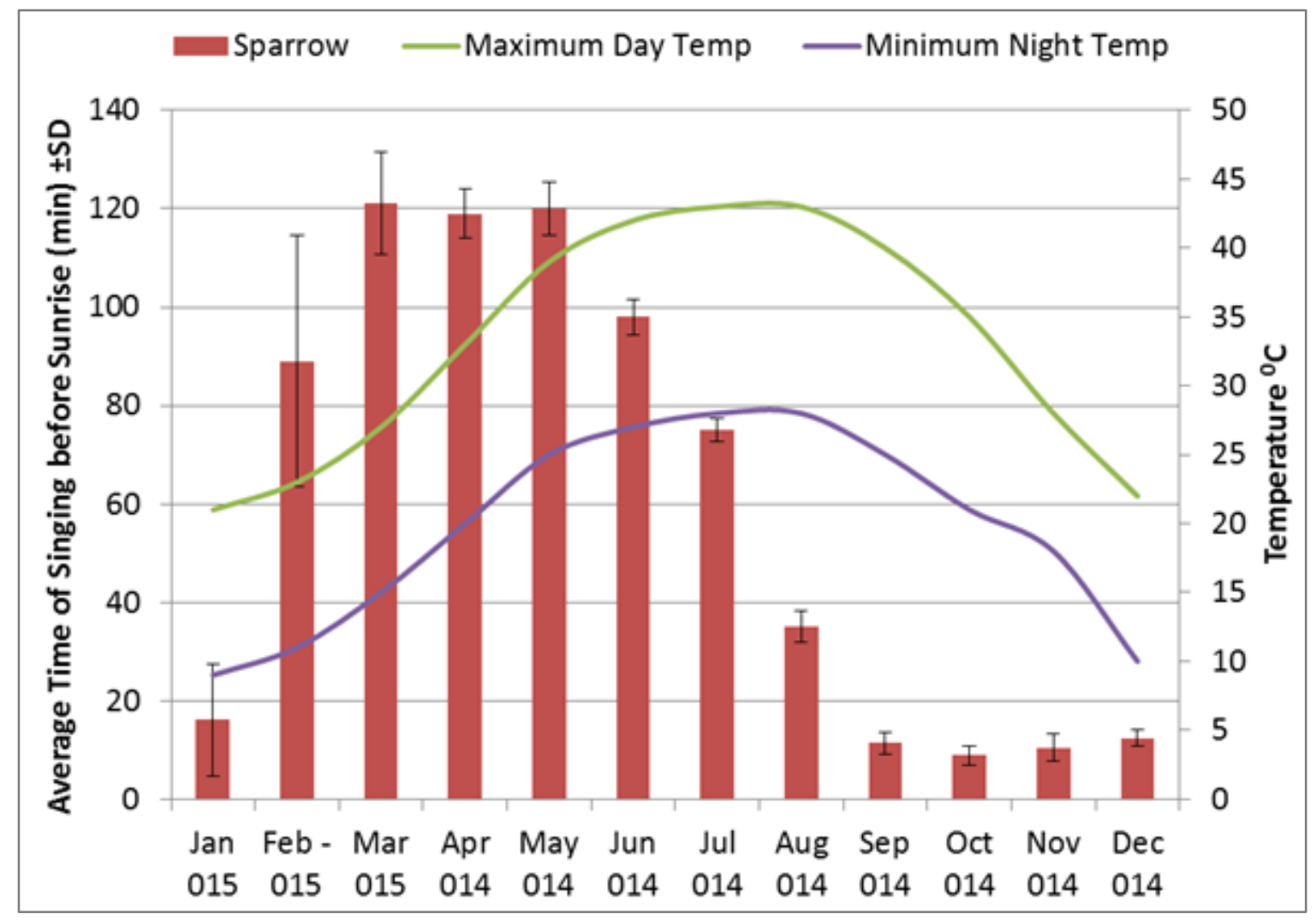

Figure 2. Relationship between the average maximum day and minimum night temperatures and start of singing for a whole year 


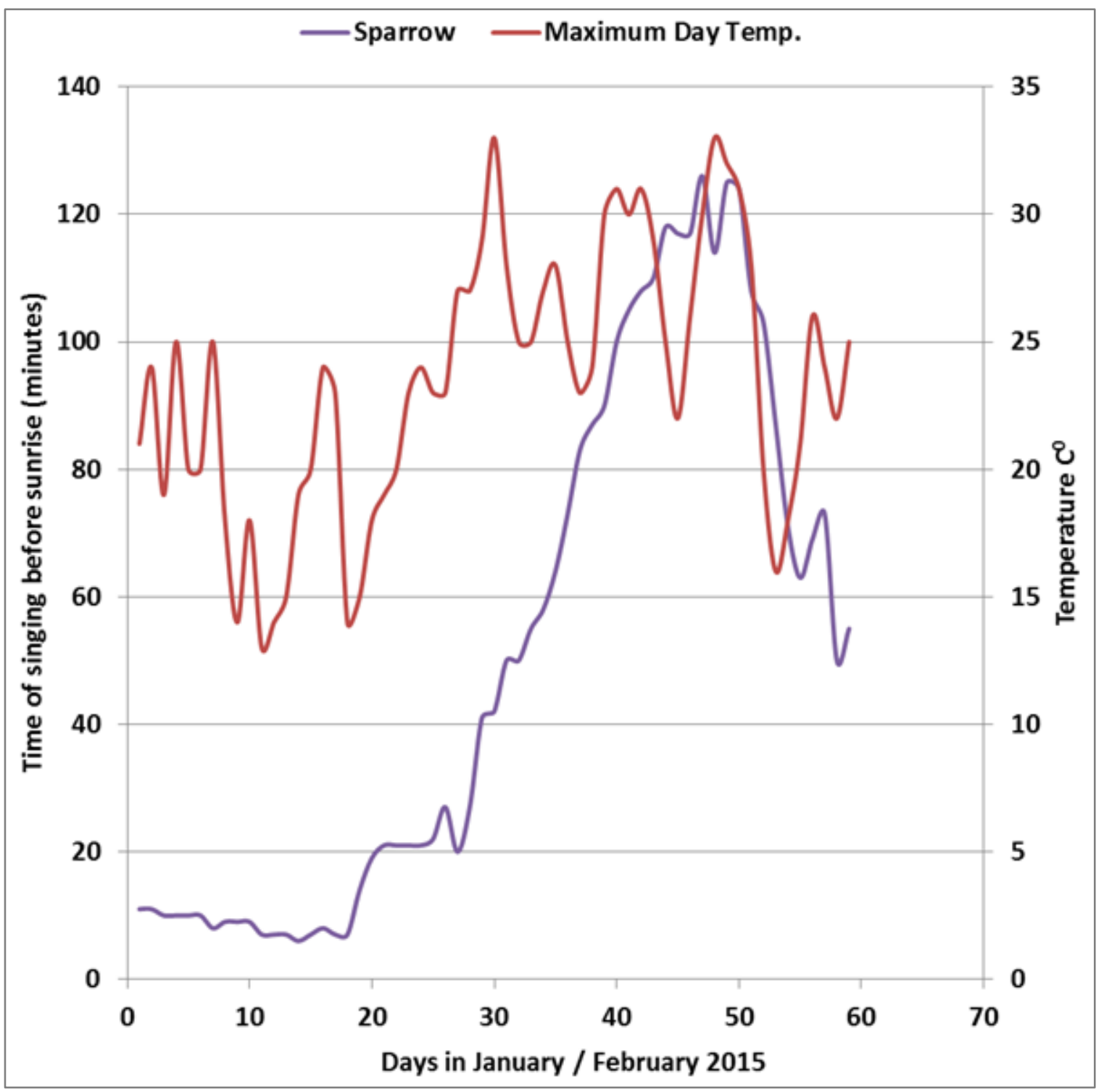

Figure 3. Effect of day/night fluctuations in ambient temperatures on the start of singing for sparrows for the months of January and February 2015 


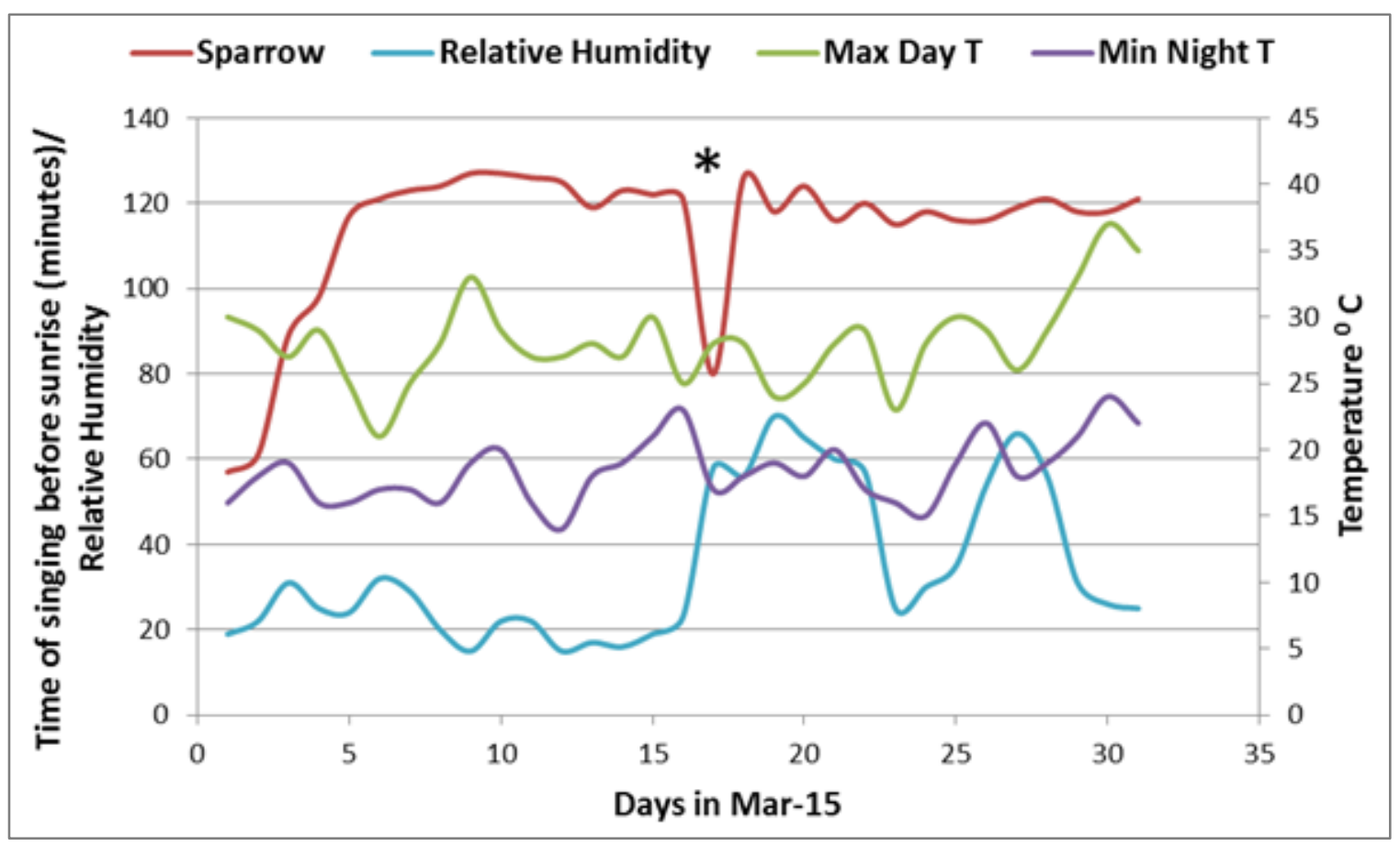

Figure 4. Effect of humidity and day/night temperatures on the early start of singing of sparrows for March 2015 (* Rain at time of singing)

Similarly Figure 2 shows the relationship between start of singing for a whole year and the average maximum day and minimum night temperatures. It is noticed that increasing temperatures early in the year in January and February after continued lower temperatures in November and December induce early singing for both birds studied. The return to later singing towards the end of summer months is mainly associated with decreasing photoperiod but not temperature.

Figure 3 shows the effect of daily/nightly fluctuations in ambient temperatures on the start of singing for sparrows for the months of January and February 2015. It shows that start of singing fluctuates in a manner that is clearly dependent on ambient temperatures. It is noted that shift to early singing starts if day temperatures start to exceed $30{ }^{\circ} \mathrm{C}$ and night temperatures start to exceed $20{ }^{\circ} \mathrm{C}$ and it will revert to late singing if day temperature re less than $20^{\circ} \mathrm{C}$ accompanied by night temperatures of less than $10{ }^{\circ} \mathrm{C}$.

The data in figure 3 and 4 was used to find if there is a real positive correlation between day/night temperatures and start of singing using Pearson correlation coefficient. Table 1 shows the results of statistical analysis. It shows that for sparrows: the correlation between the early morning chorus and both day temperature (Pearson correlation coefficient $\mathrm{r}=$ $0.652, \mathrm{p}<0.0001$ ) and night temperature (Pearson correlation coefficient $\mathrm{r}=0.710, \mathrm{p}<0.0001$ ) was highly significant.

There was two occasions of dusty weather. The first was an overnight moderate dust storm on $\left(12^{\text {th }}\right.$ of February), the other was a heavy strong dust storm that started on the afternoon of the $1^{\text {st }}$ of April and lasted overnight. At dawn the storm preceded and there was moderate to light windy dusty conditions. Both did not affect the start of dawn chorus. There was two occasions of rain $\left(7^{\text {th }}\right.$ and $17^{\text {th }}$ of
March). First occasion was overnight rain that had stopped before the onset of dawn chorus. This had no effect on start of singing. In the second occasion there was lightening, thunder accompanied by moderate rain which continued through the expected time of start of singing. In this occasion dawn chorus was delayed for both bulbuls and sparrows for almost 40 minutes from expected time. It resumed shortly after rain stopped.

The effect of humidity on start of dawn chorus was studied for the month of March 2015 since there was occasional rain and showers and a marked increase in humidity. Figure 4 shows that there was no effect of humidity on the early start of singing of the two bird species. It also shows and confirms that fluctuations in temperatures in March have no effect on start of singing (table 1). Therefore, in March where early singing is the norm, there was no major/dramatic changes in temperature but it was marked by major changes in humidity, the start of singing in March is not found to be correlated with temperature or humidity.

Table 1. Correlation and significance between start of singing and day, night temperatures and humidity.

\begin{tabular}{|c|c|c|}
\hline \multirow{2}{*}{ Variable } & \multicolumn{2}{|c|}{ Sparrows } \\
\cline { 2 - 3 } & $\mathrm{r}$ & $\mathrm{p}$-value \\
\hline Jan - Feb 2105 & 0.652 & $<0.0001$ \\
\hline Day temperature & 0.710 & $<0.0001$ \\
\hline Night temperature & & \\
\hline March 2015 & -0.077 & 0.680 \\
\hline Day temperature & 0.173 & 0.351 \\
\hline Night temperature & 0.063 & 0.737 \\
\hline Humidity & &
\end{tabular}

r: Pearson correlation coefficient 


\section{Discussion}

There are many factors that might affect all aspects of dawn chorus. Temperature is a major parameter of any regional climate and can affect sun irradiance [16]. There is a positive relationship between overnight temperatures and singing behavior (amount of singing) in cold climates $[17,14]$. In cold nights birds will have more fat reserves and this will determine song output and bird behavior $[18,19]$. Therefore, it was found that start of dawn chorus in wild birds can be delayed by supplementary feeding [20].

In the breeding season birds use singing as a form of display to repel rivals and attract mates [21] and this depends on proximal factors such as ambient temperature, time of the day and energy reserves. Nocturnal birds such as the owl Athene noctua increased their activity towards dusk irrelevant of ambient temperature [22].

This study shows that longer days (short nights) induce a shift to early singing. This is paradoxical because it might be suggested that birds need to sleep more and exhibit delay in start of singing at dawn but is widely accepted that sun light (amount of light and photoperiod) is the main initiator of dawn chorus [23]. The start of early singing shown in our study can also be explained by the fact that increased day length (photoperiod) coincides with warmer temperatures and the beginning of the breeding season. But what is very interesting in our study is that it shows that within this frame, variations in day to day temperature can influence the time of day to day singing.

The effect of seasonal variations, noise and light pollution on the start of singing was investigated in three bird species including sparrows in a Mediterranean moderate climate [13]. It was concluded that the start of singing was not directly affected by fluctuations in daily temperatures and was not attributed to artificial (street lights), moonlight lighting or noise pollution. The same studies showed that heavy precipitation and heavy cloud cover could delay the start of singing. There is some agreement with the study by Bruin et al. [24]. Similarly different geographical locations and altitude but with varying temperatures did not affect start of dawn chorus when comparing two locations one in Palestine and the other in Jordan [25].

This current study supports an earlier investigation which compared singing start times of bulbuls and sparrows in a different location in mid-town Riyadh / Saudi Arabia to another location in Tulkarm / Palestine [26] which showed that temperature could be the direct effector of dawn chorus start time.

This makes us ask the question: Is this a climate induced change and why? Evidence shown in our data suggests that this is the case. There is evidence that climate variability and geographical location affect song behavior in birds [27]. It was also suggested that harsh environmental conditions could induce the evolution of intraspecific divergence in birds and mammals [28]. We can presume that this very early start of singing is designed to give birds extra time to sing and to forage before sunrise where it will be really very hot to continue with their activities. Birds at this location were observed foraging well before sunrise (more than 1 hour) but it must be mentioned that there was enough street lighting.

It must also be mentioned that the observed effect of fluctuating ambient temperature can only be seen during January and February for three reasons. First, it comes after colder, short day months of November and December. Second, it coincides with warmer, longer days and start of breeding season. Third, big fluctuations in daily temperatures can occur.

It is also expected that birds will continue early singing once they start but it is noticed that they can switch back to late singing if temperature drops significantly. So it can be assumed that the threshold temperature to shift to early singing is $\geq 30{ }^{\circ} \mathrm{C}$ during days and $\geq 20{ }^{\circ} \mathrm{C}$ during nights if it comes after colder months and will shift back to later singing times if day temperature is $\leq 20{ }^{\circ} \mathrm{C}$ and night temperature is $\leq 10^{\circ} \mathrm{C}$.

Therefore, start of singing for a sparrow is prone to fluctuations in temperature in January and February only. They start early singing in January / February and will revert to late singing towards the end of summer when days start to get shorter despite the presence of hot stable temperatures. The shift to late singing in late summer is not temperature dependent and can be attributed to decreasing photoperiods (shorter days).

The presence of moderate or heavy dust overnight did not affect the start of singing. It was not possible to study the effect of precipitation because there was no heavy continuous precipitation during the period studied. Therefore dust and rain will only affect start of singing unless heavy and continue throughout the expected time of singing. Similarly the effect of artificial lightning couldn't be studied due to the presence of much night lights in the sites of investigation. This also rendered the studying of effect of moonlight meaningless.

Street lighting was found to cause dawn and dusk chorus to come earlier in the year [29]. Another factor that has been shown to cause earlier singing in birds is noise pollution $[30,31]$. Another study said that light pollution rather than noise pollution affects daily timing of dawn and dusk chorus [32]. We can conclude that traffic and urban noise pollution had no effect on the start of singing when comparing the present study with an earlier study for the same birds at a different more noisy ( $\geq 65 \mathrm{~dB}$ ) urban location [26].

Humidity may affect light transmission and scattering [33, $34]$ and also it may affect refraction of sound waves [7,35]. Humidity also been shown to affect animal behaviour, i.e. foraging activity of ants was significantly affected by relative humidity [36]. Therefore, it was thought that in a very dry hot climate high relative humidity might affect the start of dawn chorus in the studied birds. Our results show that humidity had no effect on the start of singing. Similarly, dust and pollutants in the air might reduce the amount of light available or disturb sound waves $[37,38]$ and therefore expected to affect start of singing for birds. There are no reports regarding how dust would influence the start of dawn 
chorus. Our study did not show an effect of moderate dusty conditions on start of singing but this has to be confirmed if and when a persistent strong dusty storm occurs.

Birds in general sing early at the coldest time of the day because they might have less fat reserves left [39]. Therefore, we can say that when temperatures start to go up early in the season (sometime in January), birds will have more energy reserves than they are used to, so they start singing earlier but if temperatures drop too much during these times they switch back to later singing. This might be supported by the report that suggests that lower overnight temperatures are found to decrease song output [18]

Finally, our results regarding effect of temperature and precipitation are in good agreement with Bruni et al. study [24].

In summary, we can conclude that birds will shift to early singing for three combined reasons: time of the year, increasing temperatures, and breeding season. Only fluctuations in ambient temperature in this time of the year are found to be accompanied by changes in start of singing in both birds studied. The plausible explanation is that these birds have evolved to commence their activities upon increasing temperatures by starting to sing as early as possible before the rise of the very hot sun and that temperature overrides other factors (breeding, photoperiod) in determining start of singing early in the season. This conclusion might be supported by the study that suggested that environments may ultimately affect evolution in bird populations [18].

\section{REFERENCES}

[1] Xia C, Wei C, Lloyd H, Liu J, Wu Q and Zhang Y (2014). Dawn Singing Intensity of the Male Brownish-Flanked Bush Warbler: Effects of Territorial Insertions and Number of Neighbors. Ethology, 120, 1-7.

[2] Staicer CA, Spector DA and Horn AG (1996). The dawn chorus and other diel patterns in acoustic signaling. In: Kroodsma DE, Miller EH (eds) Ecology and evolution of acoustic communication in birds. Cornell University Press, Ithaca, pp 426-453.

[3] Bruni A, Mennill DJ, Foote JR (2014). Dawn chorus start time variation in a temperate bird community: relationship with seasonality, weather, and ambient light. Journal of Ornithology, 155, 877-890.

[4] Hutchinson JC (2002). Two explanations of the dawn chorus compared: how monotonically changing light levels favour a short break from singing. Animal Behavior, 64, 527-539.

[5] Brown TJ, Handford P (2003): Why birds sing at dawn: the role of consistent song transmission. Ibis 145:120-129.

[6] O'Connor RJ and Hicks RK (1980): The influence of weather conditions on the detection of birds during Common Birds Census fieldwork. Bird Study, 27, 137-151

[7] Henwood K and Fabrick A (1979). A quantitative analysis of the dawn chorus: Temporal selection for communicatory optimization. The American Naturalist, 114(2), 260-265

[8] Foote JR, Fitzsimmons LP, Mennill DJ, Ratcliffe LM (2011). Male black-capped chickadees begin dawn singing earlier in response to simulated territorial insertions. Anim. Behav., 81, $871-887$

[9] Miller MW (2006). Apparent effects of light pollution on singing behaviour of American Robins. The Condor, 108(1), 130-139.

[10] Fuller RA, Warren PH and Gaston KJ (2007). Daytime noise predicts nocturnal singing in urban birds. Biology Letters 3, 368-370.

[11] Kempenaers B, Borgstrom P, Loes P, Schlicht E and Valcu M (2010): Artificial Night Lighting Affects Dawn Song, Extra-Pair Siring Success, and Lay Date in Songbirds. Current Biology, 20, 1735-1739.

[12] Arroyo-Solis A, Castillo JM, Lopez-Sanchez JL, Slabbekoorn $H$ (2013). Experimental evidence for an impact of anthropogenic noise on dawn chorus timing in urban birds. Journal of Avian Biology 44, 288-296.

[13] Hasan N. (2010). The effect of environmental conditions on the start of dawn singing of blackbirds and bulbuls. Jordan Journal Biological Sciences, 3(1), 13-16.

[14] Garson PJ, Hunter Jr ML (1979). Effects of temperature and time of year on the singing behavior of Wrens and Great Tits. Ibis, 121, 481-487.

[15] Thomas RJ (1999). Two tests of the stochastic dynamic programming model of daily singing behavior in birds. Anim Behav, 57, 277-284.

[16] Reid GC (1991). Solar total irradiance variations and the global sea surface temperature record. Journal of Geophysical Research, 96 (2), 2834-2844.

[17] Strain JG and Mumme RL (1988). Effects of food supplementation, song playback and temperature on vocal territorial behavior of Carolina wrens. The Auk, 105, 11-16.

[18] Barnett CA, Briskie JV (2007). Energetic state and the performance of dawn chorus in silvereyes (Zosterops lateralis). Behavioral Ecology and Sociobiology, 61, 579-587.

[19] Thomas RJ, Sze'skely T, Cuthill IC, Harper DG, Newson SE, Frayling TD and Wallis P (2002). Eye size in birds and the timing of song at dawn. P Roy Soc B-Biol Sci , 269, 831-837

[20] Saggese K, Korner-Nievergelt F, Slagsvold T and Amrhein F (2011). Wild bird feeding delays start of dawn singing in the great tit. Animal Behaviour, 81, 361-365

[21] Maynard Smith, J., and D. Harper, (2003). Animal Signals. pp. 162, Oxford University Press, Oxford.

[22] Hardouin LA, Robert D and Bretagnolle V (2008). A dusk chorus effect in a nocturnal bird: support for mate and rival assessment functions. Behav Ecol. Sociobiol., 62, 1909-1918.

[23] Thomas RJ and Cuthill IC (2002). Body mass regulation and the daily singing routines of European robins. Animal Behaviour, 63, 285-295.

[24] Chong K-F, Lee C-W (2009). Influences of Temperature, Relative Humidity and Light Intensity on the Foraging 
Activity of Field Populations of the Long-legged Ant, Anoplolepis gracilipes (Hymenoptera: Formicidae). Sociobiology, 54(2), 531-538.

[25] Hasan N (2011). Effect of seasonal variation, altitude and geographical location on the onset of dawn chorus in three bird species in Middle East. The open ornithology Journal, 4, $30-34$

[26] Hasan N (2011). Comparison of the onset of dawn chorus of bulbuls and house sparrows in two different locations: effect of climate, noise and light pollution. Research Opinions in Animal \& Veterinary Sciences, 1(4), 220-225.

[27] Botero CA, Boogert NJ, Vehrencamp SL, Lovette IJ (2009). Climatic Patterns Predict the Elaboration of Song Displays in Mockingbirds. Current Biology, 19, 1151-1155.

[28] Botero CA, Dor R, Mc Cain CM, Safran RJ (2103). Environmental harshness is positively correlated with intraspecific divergence in mammals and birds. Molecular Ecology 23, 259-268.

[29] Da Silva A, Valcu M, Kempenaers B (2015). Light pollution alters the phenology of dawn and dusk singing in common European songbirds. Philosophical Transactions B. 370, 20140126.

[30] Gil D, Honarmand M, Pascual J, Perez-Mena E, Garcia CM (2014). Birds living near airports advance their dawn chorus and reduce overlap with aircraft noise. Behavioral Ecology, 1-9. doi: 10.1093/beheco/aru207.
[31] Nordt A, Klenke R (2013). Sleepless in town: drivers of the temporal shift in dawn song in European blackbirds. Plos one, $8, \mathrm{e} 714716$.

[32] Da Silva A, Samplonius JM, Schlicht E, Valcu M, Kempenaers B (2014). Artificial night light rather than traffic noise affects the daily timing of dawn and dusk singing in common European songbirds. Behavioral Ecology. doi: 10.1093/beheco/aru103.

[33] Mehrabani A and Golnabi H (2011). Investigation of the humidity effect on the air refractive index using an optical fiber design. Journal of Applied Sciences, 11(16), 3022-3027.

[34] Panjwani M K and Narejo GB (2014). Effect of Humidity on the Efficiency of Solar Cell (photovoltaic). International Journal of Engineering Research and General Science. 2(4), 499-502

[35] Bohn DA (1988). Environmental Effects on the Speed of Sound. J. Audio Eng. Soc., Vol. 36, No. 4, 1988.

[36] Endler JA (1987). Predation, light intensity, and courtship behaviour in Poecilia reticulata. Animal Behaviour, 35, 1376-1385.

[37] Endler JA (1997). Effect of air pollution on forest light environment. Int. J.R. Clemmons, and R. Buchholz, ed. Behavioral Approaches to Conservation in the Wild. Cambridge: Cambridge University Press. pp 350.

[38] Beaulieu M and Sockman KW (2012). Song in the cold is 'hot': memory of and preference for sexual signals perceived under thermal challenge. Biology Letters. 8, 751-753. 